cepts." It fits exactly the poundals, slugs, geepounds, engineers' unit of mass, gravitals, micro-speedals, kinetic unit, scientific unit, absolute and gravitational systems, "concepts of mass," "force is the space "rate at which work in foot pounds is done, it is also the time rate at which momentum is produced or destroyed" (Perry's "Calculus") and all such pedagogical rubbish.

Our first object is to get the student into a position where he can solve such simple problems as he sees in actual work about him, and a certain amount of ignorance which would be very lamentable on the part of myself and your other contributors, is highly praiseworthy in the student.

Good! Now will Professor Wilson examine the simple problem I have given and my method of solving it and get one of his instructors to experiment on the method with some freshmen students and report the result? "Try it on the dog." Test it not only by the canons of logic and of common sense, but also by experience.

Any student knows what a weight of four pounds is.

Of course he does, until he begins the study of physics; then he may be in some doubt about it. He knows that it is a piece of metal with " 4 lb." stamped on it, but when he is told that that is not a weight, but mass, and that a weight of four pounds means a force of four pounds, also that a mass is "the constant ratio of force to acceleration," and that "he can not acquire the desired ideas of mass and inertia until after the ideas of force and acceleration have been accepted," it is no wonder that he becomes confused, and replies to the simple question, "What is force?" "The time-rate of the change of momentum," quoting from the text-book, without knowing what the words mean.

\section{WM. KenT}

\section{A MNEMONIC COUPLET FOR GEOLOGIC PERIODS}

Several years of experience in teaching geology led me, some time since, to the invention or discovery of the following scheme for helping students to remember the order of geologic periods.
The form offered here is adapted to the plan presented in Chamberlin and Salisbury's " College Geology," which is widely used. It may be modified without serious difficulty to suit other time divisions.

Neglecting the Pre-Cambrian, somewhat as common histories do pre-historic time, and also the recent epoch, we take the periods of the Paleozoic era, Cambrian, Ordovician, Silurian, Devonian, Mississippian, Pennsylvanian and Permian; of the Mesozoic, Triassic, Jurassic, Comanche and Cretaceous; and of the Cenozoic, Eocene (Oligocene), Miocene, Pliocene and Pleistocene.

Taking the first syllable of each period, and adding the termination ice to the Permian to commemorate the glacial epoch of that time, and also to rhyme with "Pleis," which also reminds one of the better known epoch of the same sort, we have the following jingle:

$$
\begin{aligned}
& \text { Cam.Or.Sil.De. } \\
& \text { Miss.Penn.Perm-ice, } \\
& \text { Tri.Ju.Co.Cre. } \\
& \text { E.(Ol.).Mi.Pli.Pleis. }
\end{aligned}
$$

Some of the divisions here counted periods may be more fittingly called epochs, but that makes no difference with the order.

J. E. TODD

\section{UNIVERSITY OF KANSAS}

\section{VARIATION IN GENOTHERA HEWETTI}

DR. G. H. SHULL ${ }^{1}$ recently published a paper on "A Peculiar Negative Correlation in Enothera Hybrids," in which he showed that in certain cultures dull dark red stems were associated with entirely green buds, and gave other evidence indicating that the appearance of anthocyan in one part of the plant by no means involved its appearance in other parts.

I have this year a series of plants of $E_{\text {Eno- }}$ thera hewetti, descended from the original plant brought from the Rito de los Frijoles, New Mexico, in 1912. This is a relative of $C E$. hookeri, and quite distinct from the species used by Dr. Shull. Nevertheless, it varies in pigmentation along practically the same lines.

1 Journal of Genetics, IV., 1914, p. 83. 